\title{
Synchronous diagnosis of primitive papillary adenocarcinomas: beyond the realm of probability
}

\author{
Diagnóstico simultâneo de adenocarcinomas papilares \\ primitivos: além da probabilidade
}

\author{
Pedro Gonçalo de Silva Ferreira, Paulo Matos, António Jorge Gouveia Ferreira
}

\section{To the Editor:}

We report the recent case of a 74-year-old female who had no relevant history of smoking or occupational history and presented to the emergency room with a two-week history of dyspnea on exertion. There was no evidence of a recent respiratory infection, peripheral edema, or orthopnea. The patient reported a history of arterial hypertension and osteoporosis and was being treated with ramipril, fluvastatin, and ibandronate.

Physical examination revealed that the patient was apyretic and breathed normally, with an $\mathrm{SpO}_{2}$ of $98 \%$, a blood pressure of $116 / 68 \mathrm{mmHg}$, and an HR of $91 \mathrm{bpm}$. In addition, heart auscultation was regular, without heart murmurs and with absent breath sounds at the right lung base, accompanied by dullness to percussion and absent vocal fremitus in this topography.

A chest $X$-ray showed a dense opacity in the lower half of the right lung field, consistent with massive, apparently free pleural effusion.

An initial diagnostic thoracentesis revealed a serosanguineous exudative effusion $(\mathrm{pH}, 7.33$; proteins, $4.5 \mathrm{~g} / \mathrm{dL}$; lactate dehydrogenase, 728 $\mathrm{lU} / \mathrm{mL}$; glucose, $38 \mathrm{mg} / \mathrm{dL}$; albumin, $3.0 \mathrm{~g} / \mathrm{dL}$ ), with a predominance of lymphocytes (60\%) and an adenosine deaminase level of $10.6 \mathrm{IU}$. The first cytopathological analysis was negative, as was the microbiological study.

The patient had a neuron-specific enolase level of $16 \mathrm{U} / \mathrm{mL}$ and a cancer antigen 125 level of $124 \mathrm{U} / \mathrm{mL}$. Blood gas analysis indicated mild hypoxemia on room air. Flexible bronchoscopy showed only thickening of the emergence of the right upper lobe bronchus, the biopsy of which showed hyperplasia of basal cells.

The second cytopathological analysis of the fluid obtained via a second thoracentesis led to the suspicion of papillary adenocarcinoma of unknown origin. A chest CT scan (Figure 1) revealed right pleural effusion without nodular pleural thickening or mediastinal/hilar adenopathy, and the assessment of the lung parenchyma was inconclusive because of effusion-related atelectasis.

By this time, the working diagnoses were papillary adenocarcinoma of the thyroid with pleural metastasis, papillary adenocarcinoma of the lung with pleural and thyroid metastasis, or synchronous papillary adenocarcinoma of the lung with pleural metastasis and papillary adenocarcinoma of the thyroid.

On the basis of those diagnoses, the pleural fluid was examined for expression of tumor markers, including squamous cell carcinoma, Cyfra 21-1, CA 19-9, and thyroglobulin (TG), and the patient was referred for medical thoracoscopy and ultrasonography of the thyroid gland.

The thyroid ultrasonography showed heterogeneous nodular hyperplasia, and aspiration biopsy of the largest nodule revealed "primitive/ secondary" papillary carcinoma, which was subsequently confirmed (in a total thyroidectomy specimen) to be primitive papillary carcinoma of the thyroid with immunohistochemical expression of thyroglobulin, TTF-1, CK19, and galectin-3 (Figure 2).

The pleural fluid was negative for thyroglobulin but positive for Cyfra 21-1 and CA19-9. The medical thoracoscopy revealed nonspecific nodular lesions at the level of the parietal pleura, and the pleural biopsies revealed metastatic papillary adenocarcinoma of the lung, on the basis of positive expression of TTF-1, vimentin, and CK7 and negativity for TG.

A second CT scan, performed after drainage of the fluid, made it possible to unveil a subpleural nodular formation in the medial segment of the middle lobe, with contrast enhancement, suspected to be the primitive lung injury.

Therefore, we established the diagnosis of synchronous papillary adenocarcinoma of the 

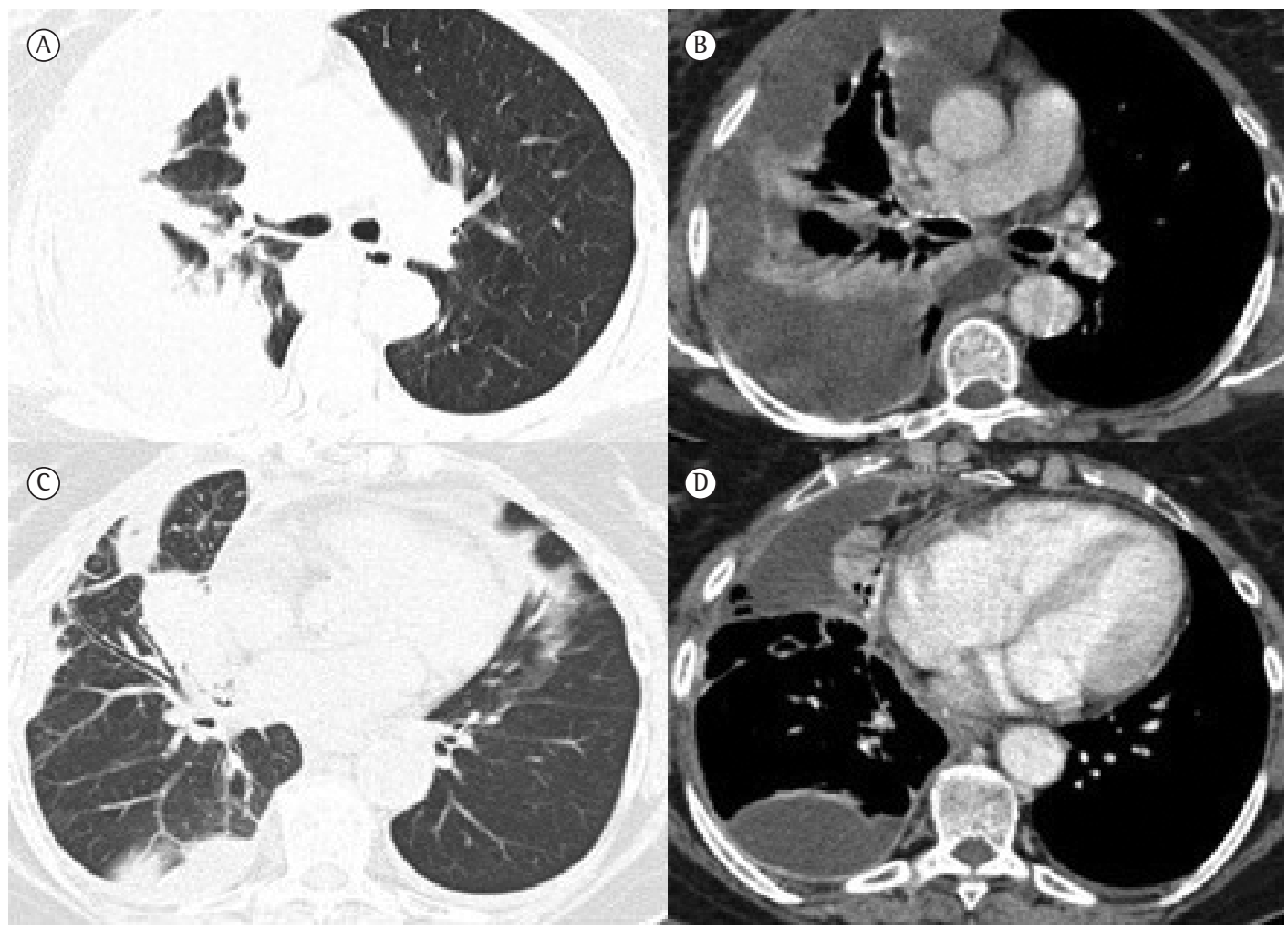

Figure 1 - Chest CT scans. In A and B, initial CT scan showing right pleural effusion with ipsilateral parenchymal atelectasis. In C and D, post-drainage CT scan showing residual sites of pleural effusion with a nodular formation in the medial segment of the middle lobe, with contrast enhancement.

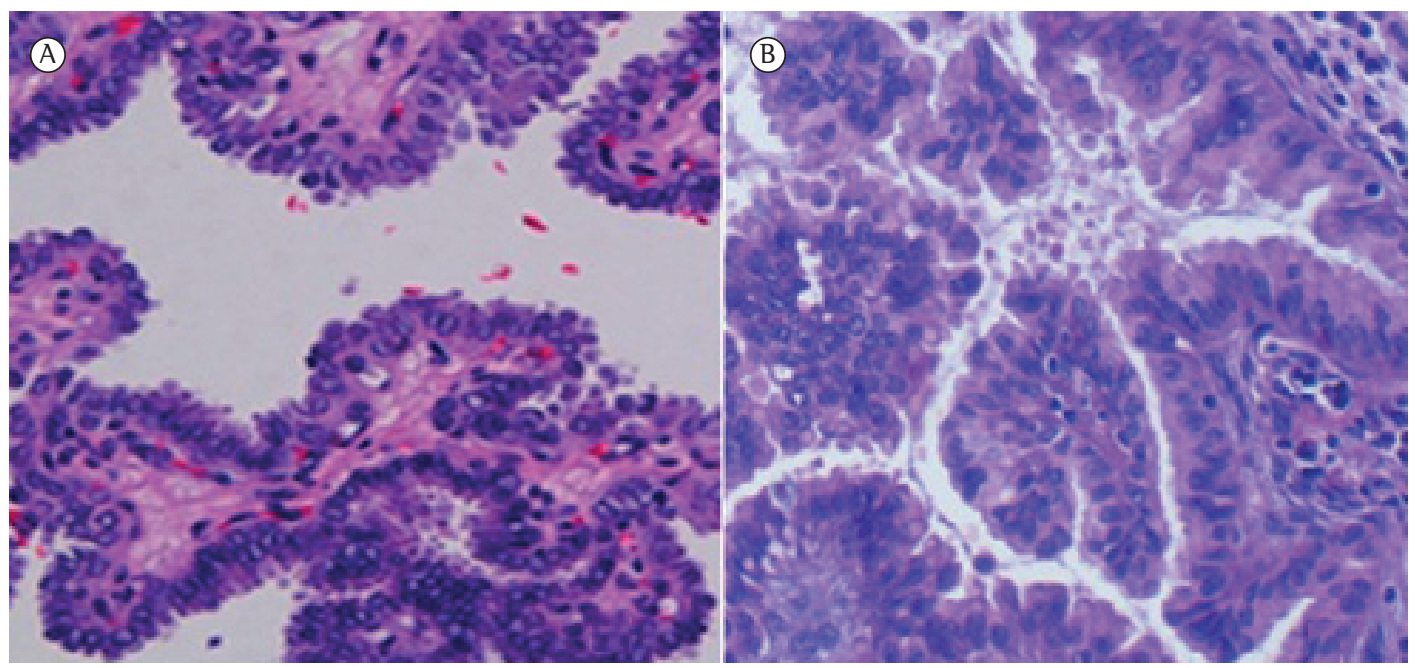

Figure 2 - Photomicrographs showing papillary adenocarcinoma of the lung in A ((HEE; magnification, $\times 20$ ) and papillary adenocarcinoma of the thyroid in B (H\&E; magnification, $\times 100)$.

thyroid and stage IV papillary adenocarcinoma of the lung with pleural metastasis. The patient underwent pleurodesis and began chemotherapy with cisplatin and gemcitabine, with partial response after three cycles.
Although distant metastases of papillary adenocarcinoma of the thyroid are rare, cases presenting as malignant plural effusion have been reported, ${ }^{(1-5)}$ and, in some cases, the final diagnosis was only confirmed by analysis of a 
total thyroidectomy specimen..$^{(1)}$ In contrast, lung adenocarcinoma is the type of cancer that most commonly metastasizes to the pleura, resulting in poor prognosis, ${ }^{(6)}$ and its papillary variant is unusual. There are reported cases associated with thyroid metastases. ${ }^{(5,7,8)}$

We emphasize that, in cases like the present one, with diagnosis of synchronous cancers showing the same pattern of differentiation, etiologic determination of malignant pleural involvement is of utmost importance because, even in disseminated disease, the difference in mean survival between papillary adenocarcinoma of the thyroid (a 5-year survival rate of 56\%) and papillary adenocarcinoma of the lung with pleural dissemination (an average of 3-5 months) is remarkable.

In circumstances in which diagnostic discrimination is poor, such as that of the present case, analysis of immunohistochemical expression is a key differentiating element. In particular, since TTF- 1 is expressed in the lung and in the thyroid, the finding of TG in the pleural fluid, and especially in the histological specimen, can facilitate the differential diagnosis. ${ }^{(9)}$

$$
\begin{gathered}
\text { Pedro Gonçalo de Silva Ferreira } \\
\text { Resident in Pulmonology, Coimbra } \\
\text { Hospital and University Center, } \\
\text { Coimbra, Portugal }
\end{gathered}
$$

Paulo Matos

Resident in Pulmonology, Coimbra Hospital and University Center, Coimbra, Portugal

\section{António Jorge Gouveia Ferreira Pulmonologist, Coimbra Hospital and University Center, Coimbra, Portugal}

\section{References}

1. Pérez Vega C, Lecube Torelló A, Narváez García J, Vilaseca Momplet J. Pleural metastasis as presenting form of papillary thyroid microcarcinoma: an exceptional case [Article in Spanish]. Rev Clin Esp. 2003;203(4):217-8. http://dx.doi.org/10.1157/13045550 PMid:12681214

2. Vassilopoulou-Sellin R, Sneige N. Pleural effusion in patients with differentiated papillary thyroid cancer. South Med J. 1994;87(11):1111-6. http://dx.doi. org/10.1097/00007611-199411000-00010

3. Vernon AN, Sheeler LR, Biscotti CV, Stoller JK. Pleural effusion resulting from metastatic papillary carcinoma of the thyroid. Chest. 1992;101(5):1448-50. http:// dx.doi.org/10.1378/chest.101.5.1448 PMid:1582317

4. Jung KH, Seo JA, Lee J, Jo WM, Kim JH, Shim C. A case of papillary thyroid cancer presenting as pleural effusion. Tuberc Respir Dis (Seoul). 2008;64(4):314-17. http://dx.doi.org/10.4046/trd.2008.64.4.314

5. Berge T, Lundberg S. Cancer in Malmö 1958-1969. An autopsy study. Acta Pathol Microbiol Scand Suppl. 1977;(260):1-235. PMid:269649

6. NCCN Clinical Practice Guidelines in Oncology. Non Small Cell Lung Cancer version 2.2010. Fort Washington: National Comprehensive Cancer Network; 2010.

7. Singh R, Lehl SS, Sachdev A, Handa U, D'Cruz S, Bhalla A. Metastasis to thyroid from lung carcinoma. Indian J Chest Dis Allied Sci. 2003;45(3):203-4. PMid:12866639

8. Nakhjavani MK, Gharib H, Goellner JR, van Heerden JA. Metastasis to the thyroid gland. A report of 43 cases. Cancer. 1997;79(3):574-8. http://dx.doi. org/10.1002/(SICl)1097-0142(19970201)79:3<574::AIDCNCR2 1>3.0.CO;2-

9. Porcel JM, Vives M, Esquerda A, Salud A, Pérez B, Rodríguez-Panadero F. Use of a panel of tumor markers (carcinoembryonic antigen, cancer antigen 125, carbohydrate antigen 15-3, and cytokeratin 19 fragments) in pleural fluid for the differential diagnosis of benign and malignant effusions. Chest. 2004;126(6):1757-63. http:// dx.doi.org/10.1378/chest.126.6.1757 PMid:15596670 